\title{
Supervisão em Serviço Social diante da precarização no mundo do trabalho: uma perspectiva helleriana
}

\author{
Gleny Terezinha Duro Guimarães \\ (PUC-RS)
}

\author{
Paulo Roberto Martins \\ Universidade Federal de Santa Maria (UFSM)
}

Supervisão em Serviço Social diante da precarização no mundo do trabalho: uma perspectiva helleriana Resumo: O artigo reflete sobre as formas como a precarização das condições de trabalho têm se manifestado no cotidiano do processo de supervisão no Serviço Social, a partir dos resultados de uma pesquisa qualitativa realizada no Rio Grande do Sul com assistentes sociais supervisores. O ponto de partida é a reestruturação produtiva após a década de 1970; posteriormente, relaciona as condições de precarização com o duplo sentido que Agnes Heller atribui ao contato cotidiano, um derivado da divisão social do trabalho e o outro da dependência provisória entre os indivíduos, enquanto atividade política consciente. Finaliza demonstrando que a maioria dos indicadores de precarização que se manifestam nas condições de trabalho geralmente são (in)visibilizados sob o fenômeno falta de tempo.

Palavras-chave: Supervisão em Serviço Social. Agnes Heller. Trabalho.

\section{Supervision in Social Service Considering Increased Precariousness in the World of Labor: a Hellerian Perspective}

Abstract: The article reflects on how increasingly precarious working conditions are manifest in the daily work of supervision of social work, based on the results of a qualitative study, conducted in Rio Grande do Sul with supervisors of social workers. The study began by considering the productive re-organization since the 1970s; and then presents the conditions of increased precariousness considering the dual meaning that Agnes Heller attributes to daily contact, one derived from the social division of labor and another from the provisory dependency among individuals, as conscious political activity. It concludes by demonstrating that most indicators of precarious working conditions are generally made (in)visible by the phenomenon of the lack of time.

Keywords: Supervision in Social Work. Agnes Heller. Labor.. 


\section{Introdução}

As mudanças que vêm atingindo a sociedade capitalista determinaram a dinâmica social, econômica e política do último quartel do século 20, ocorrendo constantes transformações tanto na esfera produtiva como na orientação do Estado, o que tem resultado no ataque aos direitos sociais da classe trabalhadora e inevitavelmente se refletido no cotidiano profissional.

O processo de supervisão é um lócus privilegiado da relação profissional, pois ocorre de forma direta e acompanha um processo de formação profissional, amadurecimento pessoal, dilemas, crises e conquistas profissionais, estando articulado com as diretrizes do projeto ético-político da profissão. Este processo de formação está inserido num contexto de precarização das condições de trabalho que os profissionais supervisores de campo estão enfrentando. Isso significa que nas diversas dimensões do mundo do trabalho - organização, condições, gestão, proteção social - a precarização do trabalho se manifesta de alguma forma no cotidiano profissional.

As reflexões apresentadas neste artigo resultam de duas pesquisas qualitativas sobre supervisão em Serviço Social, realizadas com bolsa de iniciação científica ${ }^{1}$ financiada pela FAPERGS e pelo CNPq. Foi uma pesquisa qualitativa do tipo exploratório, cujo instrumento de coleta foi um questionário semiestruturado, contando com a participação de 116 profissionais. A técnica de análise das informações foi a Análise de Conteúdo. A pesquisa foi aprovada pela Comissão Científica da Unidade de Ensino à qual a pesquisa estava vinculada e atende aos seus pressupostos éticos. O preenchimento de todos os questionários foi precedido da assinatura do Termo de Consentimento Livre e Esclarecido de forma on-line, aplicado através do Programa Qualtrics.

A seguir abordaremos alguns pontos da dinâmica do capitalismo e suas transformações pós-1970, buscando dar subsídios para que se possam compreender os impactos no cotidiano do trabalho do assistente social nas suas atividades enquanto supervisor de campo.

\section{Mudanças na ordem do capital pós-1970}

Após o fim da Segunda Guerra Mundial, as economias centrais viveram processos de ampla prosperidade, com expressivos índices positivos de acumulação de riqueza e de bem-estar aos cidadãos. O Estado, influenciado pelo referencial teórico keynesiano, teve função importante na retomada dos saldos positivos na área econômica, suas ações, através do fundo público, foram importantes para financiar a reprodução do capital e também da força de trabalho, principalmente na ampliação dos direitos sociais para a classe trabalhadora, conquistados com ampla organização através dos sindicatos. Durante certo tempo, foi possível conciliar crescimento econômico com desenvolvimento social. Nos anos 1970, inicia-se uma mudança profunda, ocasionada pela crise estrutural do capital2 ${ }^{2}$, tendo como elementos desse processo na ótica liberal a falência do Estado de bem-estar social e sua política de intervenção nas relações econômicas. Essa política teria inibido o livre jogo das forças do mercado, resultando na decrescente taxa de lucro. Restaria como única saída aceitar os preceitos da ideologia neoliberal, que, em uma conjuntura de instabilidade, ganhou terreno em escala global.

A elaboração teórica e política do neoliberalismo teve seu início logo após o fim da Segunda Guerra Mundial, principalmente nos países europeus e da América do Norte (ANDERSON, 1995). Durante o seu surgimento e até meados da década de 1970, não teve condições favoráveis para se tornar hegemônico. Neste tempo histórico, o capitalismo passava por um período de grande crescimento econômico, conhecido como a idade de ouro, e por uma grande ampliação da proteção social aos trabalhadores, configurando o Estado de bem-estar social. Esse ciclo positivo de crescimento teve seu esgotamento no início dos anos 1970, principalmente pela “crise do modelo econômico pós-guerra, em 1973, quanto todo o mundo capitalista avançado caiu numa longa e profunda recessão, combinando, pela primeira vez, baixas taxas de crescimento com altas taxas de inflação" (ANDERSON, 1995, p. 10). Diante desta conjuntura, o papel do Estado passou a ser questionado, e a esfera produtiva do capitalismo passaria por importantes mudanças, afetando diretamente os trabalhadores e suas formas coletivas de organização, terreno propício para a captura da subjetividade da classe trabalhadora no processo de produção (ALVES, 2011).

Com o avanço ideológico do neoliberalismo, aprofundam-se também mudanças na esfera produtiva, advindas da crise de acumulação de capital e do esgotamento do taylorismo/fordismo enquanto concepção de gestão e organização do trabalho. A reestruturação produtiva configura-se na transição do modelo rígido de gestão do trabalho - fordista/taylorista para um mais maleável, conhecido como acumulação flexível ${ }^{3}$ (HARVEY, 2014), objetivando recuperar os ciclos positivos de acumulação de capital ${ }^{4}$, através de um sistema de inovações tecnológicas e novas modalidades de gestão da produção, que "reflete a busca [...] em elevar a taxa de lucro através do aumento da produtividade, a fim de intensificar a extração de sobretrabalho com base na revolução técnico-científica e das novas formas de gestão e organização do processo de 
trabalho" (WÜNSCH, 2013, p. 74). Além de intensificar o uso de capital constante, aumentando a composição orgânica do capital e gerando um aumento significativo nas taxas de desemprego, impactou diretamente na organização dos trabalhadores enquanto classe, fragilizando o poder dos sindicatos, frente a um cenário adverso de recessão econômica e mudança na base produtiva.

No contexto brasileiro, os anos 1960 até 1980 foram marcados pela luta contra o regime civil-militar e seus ataques aos direitos políticos, civis e sociais; houve uma ampla organização da classe trabalhadora e a criação de partidos e movimentos sociais com o propósito de apresentar um projeto alternativo para o Brasil, pautada na democracia. Nesta mesma conjuntura, o Serviço Social passou por profundas transformações, sendo a síntese deste processo a construção de um projeto profissional crítico em relação aos fundamentos da sociedade capitalista, buscando defender os interesses da classe trabalhadora (SILVA e SILVA, 2007). Na Constituição Federal de 1988 se teve amplo aparato jurídico e político na garantia de direitos sociais para os(as) trabalhadores(as). Constituíram-se importantes reformas do Estado brasileiro, que em princípio, na sua forma legal, poderia aproximar-se do Estado de bem-estar europeu, mas, devido às definições ocorridas na política econômica mundial e brasileira, tivemos na verdade uma contrarreforma do Estado (BEHRING, 2003). Os governos pós-redemocratização buscaram executar, tendo em vista a correlação de forças aqui instauradas, os princípios do Consenso de Washington, que previa a abertura econômica do país, obtenção de superávit primário para pagar os empréstimos com os organismos internacionais e equilibrar a balança comercial, flexibilização dos direitos sociais, orientação focalista para as políticas sociais, entre outras medidas. Pregava-se a liberdade do mercado, e o Estado intervencionista deveria mudar sua atuação para uma orientação regulatória, diminuindo suas ações na esfera social, para que pudesse garantir melhores condições para a reprodução do capital; como exemplo, podemos citar a privatização de alguns serviços públicos (saúde, educação, transporte, comunicação, entre outras). Esse processo foi iniciado por Fernando Collor de Mello (1990-1992) e posteriormente intensificado por Fernando Henrique Cardoso, que implementou uma série de medidas que visavam desnacionalizar a economia brasileira e privatizar importantes empresas públicas, ações que se tornaram o seu carro-chefe na política econômica ${ }^{5}$.

Nos governos de 2003 até os dias atuais, teve-se a vitória do Partido dos Trabalhadores (PT), que, em princípio, vinha para contrapor-se à concepção neoliberal. O que tivemos, porém, foi o contrário. Não se derrotou o neoliberalismo; na verdade, deu-se a ele uma nova face, chamada de neodesenvolvimentismo ${ }^{6}$, o desenvolvimento possível à época de hegemonia neoliberal (BOITO Jr.; BERRINGER, 2013). A coalização política formada no governo continha forças de várias frentes, sendo a burguesia interna brasileira sua força dirigente, e reunia também a baixa classe média, o operariado urbano e o campesinato. As ideias neoliberais não foram derrotadas nas eleições, e sim aglutinadas pela correlação de forças que se formou em torno do governo petista. Nos primeiros anos, por exemplo, houve grandes debates e disputas em torno das políticas sociais universais e focalistas, demonstrando o quanto a agenda liberalizante não havia sido derrotada, mas estava inserida nas relações de força ali constituídas (FAGNANI, 2001). Outro ponto que merece destaque é referente às ações na área da política econômica, em que o governo Lula manteve "intacta a herança dos governos FHC do tripé defendido pelo Consenso de Washington (superávit primário, metas inflacionárias e câmbio flutuante)" (CASTELO, 2012, p. 614). Os primeiros anos do governo Lula tiveram o predomínio de ações de recorte neoliberal na política econômica; em seu segundo mandato, adotou medidas de tendência desenvolvimentista, mas não rompeu totalmente com os aspectos da "antiga" política (WÜNSCH, 2013). O governo Dilma prosseguiu com a mesma política econômica, onde nossa balança comercial depende cada vez mais do setor primário para obter saldos positivos. Isso não vem ocorrendo, pois, devido à crise econômica mundial, as exportações vêm diminuindo, principalmente pelo parco desenvolvimento econômico que vêm tendo os principais mercados compradores de nossos produtos, principalmente a China.

É fato que os governos petistas impactaram de forma positiva nas condições de vida da população brasileira: há indicadores positivos no combate à pobreza e à fome, através dos programas de transferência de renda, aumento das vagas no ensino superior, mesmo que a grande maioria tenha sido voltada para o ensino privado, controle da inflação e diminuição da taxa de desemprego, aumento real do salário mínimo, entre 
outros. Avanços sociais fortemente marcados pela relação público-privado, mesmo que importantes para a população trabalhadora, não mexeram na estrutura da sociedade brasileira e não conseguiram construir um projeto alternativo de desenvolvimento para o país. "O combate à concentração de riqueza não foi o alvo" (PEREIRA, 2012, p. 746); exemplo disso é a estrutura agrária brasileira, que permanece praticamente intacta.

Todo esse cenário impacta diretamente no trabalho cotidiano dos assistentes sociais. Em um cenário de recessão econômica, o financiamento das políticas sociais fica comprometido. Exemplo disso é o Projeto de Lei 131/2016, que está sendo encaminhado no Senado Federal, que prevê a retirada da participação obrigatória da Petrobras na exploração do petróleo da camada do pré-sal. Se aprovado este PL, ele afetará diretamente o financiamento da política educacional, e mais uma vez a soberania nacional será colocada em xeque, abrindo espaço para projetos que buscam novamente tornar nossas riquezas nicho de mercado para as multinacionais. As transformações que vêm ocorrendo nos últimos anos afetam diretamente os processos de trabalho em que se inserem o assistente social e as atividades de supervisão de campo. As relações estabelecidas no cotidiano não permitem que a análise dessas transformações chegue a uma compreensão mais ampla, avançando para além do imediatismo. Muitas vezes devido à sobrecarga de trabalho e à falta de tempo, a participação dos assistentes sociais e da classe trabalhadora de forma geral em espaços coletivos fica restrita a mudanças contingenciais. Essas dificuldades estão relacionadas à crescente precarização das condições de trabalho em que se insere o assistente social, especificamente no processo de supervisão.

\section{O duplo sentido do contato cotidiano em Agnes Heller e a precarização das condições de trabalho no processo de supervisão}

É no cotidiano que a particularidade do homem se produz e reproduz, mas é na genericidade que o cotidiano se transforma. É no cotidiano da supervisão que privilegiadamente se formam os assistentes sociais, vivenciando situações práticas e dilemas, É ele o espaço da práxis profissional. O cotidiano é insuprimível do real vivido bem como da relação com as mudanças societárias a que o projeto ético-político dos assistentes sociais se vincula, diante de um acirrado antagonismo na luta de classes. Sendo assim, o cotidiano implica diversas formas de contato que podem servir tanto à transformação quanto para a reificação.

Heller (1991, p. 362, 363) enfatiza a importância do contato cotidiano entre os trabalhadores, pois é através deste que a luta de classes assume força na reivindicação dos direitos humanos e sociais, tornando a mudança possível.

Sin embargo, es evidente que la lucha de clases sólo se constituye cuando millares y millares de obreros particulares tienen una actitud de igualdad con sus propios compañeros de trabajo y una actitud de desigualdad con el capitalista [...] El obrero discute la cuestión con su compañero más próximo (una vez más en contacto cotidiano personal) y todos juntos acuerdan reivindicar del capitalista un salario más alto (tenemos también aquí un contacto personal en el plano de la vida cotidiana). Los millares y millares de obreros sólo se elevan por encima del nivel de la vida y del contacto cotidianos adquiriendo la consciencia de clase (la consciencia genérica mediada por la consciencia del nosotros), cuando la conciencia de clase fundamenta su lucha integrándola en la lucha de toda la clase, ahora ya no sobre la base del contacto personal. De este modo el contacto cotidiano se convierte, en el ejemplo, en el fundamento de la actividad política consciente.

O contato cotidiano é o ponto de partida tanto na relação direta que ocorre no processo de supervisão quanto na relação contraditória e antagônica característica do sistema capitalista. Heller aponta para o cotidiano em que as relações de igualdade entre a classe trabalhadora permitem a mobilização e a reivindicação de seus interesses; neste sentido, a consciência política transformadora é resultante do contato efetivo entre os trabalhadores, a partir do momento em que compartilham uma igualdade entre si. Para Heller (1991, p. 359), o contato cotidiano não é uma relação entre o ser humano e sua essência humana, uma relação metafísica na constituição do Ser Social. O contato cotidiano também é uma relação estabelecida a partir da divisão social do trabalho, a partir do lugar em que o trabalho concreto e abstrato ocorre na sociedade. "Normalmente a través del contacto cotidiano no entran en contacto el hombre con el hombre, sino una persona que ocupa un puesto determinado en la división del trabajo con otra persona que ocupa otro puesto". Esta divisão do trabalho permeia toda a constituição social. Nesse sentido, Postone (2014, p. 148) considera o trabalho numa perspectiva trans-histórica; isto é, “o que varia historicamente é o modo de suas distribuições e administrações sociais”. Sendo assim, o contato cotidiano inerente ao processo de supervisão está relacionado com a divisão do trabalho, numa perspectiva trans-histórica. 
Para Heller o contato cotidiano possui um duplo sentido: um relacionado à divisão social do trabalho e o outro relacionado a uma dependência provisória no contato direto entre os sujeitos, sendo que ambos estão determinados pelo modo de produção: "Pero aunque los contactos personales estén fijados por el lugar en la división del trabajo y por las consiguientes costumbres, el contacto se desarrolla entre hombres particulares concretos y no entre portadores de roles” (HELLER, 1991, p. 360). Isso é complementado pelas seguintes palavras de Marx e Engels (1987, p. 35): "indivíduos determinados, que como produtores atuam de um modo também determinado, estabelecem entre si relações sociais e políticas determinadas”. Lembre-se que, para Heller (1987, p. 80), o significado do termo indivíduo pressupõe uma integração entre a particularidade e a genericidade. Em suas palavras, "o homem torna-se indivíduo na medida em que produz uma síntese em seu Eu, em que transforma conscientemente os objetivos e aspirações sociais” particulares elevando-os ao nível da genericidade. A divisão do trabalho, no contato cotidiano, estabelece uma relação de desigualdade com o capitalista e, por isso, contém inerentemente uma relação de dominação e subordinação, cuja forma de enfrentamento ocorre através da consciência de classe. O contato cotidiano decorre de uma relação pessoal na esfera da particularidade, cuja relação social poderá ser de dependência provisória, enquanto um momento de vínculo por um tempo determinado e que se constitui numa fase de transição, muitas vezes necessária; portanto, não se trata de uma dependência de subordinação ou inferioridade: "las relaciones de dependencia son siempre de naturaleza personal, mientras que las de inferioridad-superioridad reflejan el lugar que ocupan las personas de un modo permanente en la división social del trabajo y no se basan necesariamente en la dependencia personal” (HELLER, 1991, p. 360). Portanto, este tipo de dependência diz respeito a determinadas situações que são vivenciadas por um período de tempo, e ela pode ser modificada ou finalizada quando os objetivos são atingidos; por isso, caracteriza-se por uma relação contingente e provisória. Para Heller (1991), o contato cotidiano poderá estar relacionado com a divisão social do trabalho ou com uma relação direta entre os indivíduos. Esta relação, de uma forma direta ou indireta, já impõe uma condição de precarização aos processos de trabalho em que se encontram os profissionais nos mais diversos espaços sócio ocupacionais. Essa precarização, a partir da década de 1980 no Brasil, tem um significado amplo, pois atinge o trabalhador de forma que os custos com a força de trabalho sejam diminuídos e as obrigações que garantem proteção social sejam significativamente reduzidas ou eliminadas. Enfim, estamos considerando como precarização tudo aquilo que, de alguma forma, implique perda de direitos sociais, entre eles os direitos trabalhistas e previdenciários garantidos pela legislação vigente.

A perspectiva helleriana nos provoca a considerar que o trabalhador se insere na dinâmica da precarização considerando que existe uma insuprimível relação do cotidiano e do não cotidiano, isto é, a cotidianidade enquanto reino da imediaticidade e da particularidade, mas ao mesmo tempo o não cotidiano enquanto reino da genericidade em que é possível a ação crítica, consciente e transformadora. O processo de supervisão, o lócus privilegiado do contato direto entre o supervisor de campo, supervisor acadêmico e estagiário, caracteriza-se pelo paradoxo de ser um espaço derivado da divisão social do trabalho e, ao mesmo tempo, espaço do cotidiano em que o contato direto apresenta uma dependência provisória, enquanto formação profissional. Neste duplo sentido, a precarização se manifesta de formas diferentes.

Os processos de trabalho sob a égide da precarização, em especial na supervisão, podem ser constatados através de alguns indicadores ${ }^{7}$, a saber: inserção ocupacional ${ }^{8}$; rotatividade no mercado de trabalho; tempo de permanência no emprego; área de atuação profissional; espaço socioinstitucional e supervisão direta.

O indicador condição de inserção ocupacional permite constatar se o supervisor de campo tem acesso ao sistema de proteção social assegurado pela legislação vigente, seja através da carteira assinada, como estatutário ou como contribuinte da Previdência Social. A pesquisa empírica constata que a maioria dos assistentes sociais ${ }^{9}$ pesquisados possui acesso à proteção social, garantido em função do regime de trabalho, considerando que $94 \%$ dos supervisores têm um vínculo com carteira assinada de acordo com a CLT ou atuam como servidores públicos estatutários. Relacionado à inserção profissional está o indicador da rotatividade nos campos de estágio pesquisados. Estes demonstram que $73 \%$ dos profissionais trabalham na organização desde o ingresso na mesma, o que indica uma baixa rotatividade no mercado de trabalho. Porém, isso não nos exime de considerar a grave situação do desemprego estrutural, que tem atingido globalmente a classe-que-vive-dotrabalho, como diria Antunes (1995), e que certamente terá repercussões para os profissionais do Serviço Social. Por isso, é necessário considerar "os efeitos perversos da escassez do desemprego, fato que é determinante na inserção do trabalhador ao mercado de trabalho submetido a uma lógica de exploração cada vez mais intensiva" (TAVARES, 2004, p. 65). Se o indicador de rotatividade dos supervisores tem sido baixo, isso significa que o indicador de tempo de permanência no emprego tem sido um aspecto positivo. Este indicador permite identificar a "rotatividade da mão-de-obra e oferece elementos para se avaliarem os níveis de estabilidade ou de instabilidade na ocupação" (TONI, 2007, p. 33). O tempo de permanência no emprego daqueles que estão exercendo a função de supervisores indica que 50\% estão inseridos no mercado de trabalho de 01 a 
5 anos, indicando que se trata de profissionais recém-formados e que estão realizando a atribuição privativa de supervisão. Os demais 50\% dos supervisores estão distribuídos entre 06 e 30 anos de trabalho. Tanto os supervisores novos como os veteranos apresentam um índice significativo de permanência no trabalho, desde seu ingresso até a aposentadoria.

A permanência e as demais condições de mercado dos supervisores se explicam em parte porque, historicamente, o mercado de trabalho destes profissionais tem sido o setor público. Novas formas de vínculos ainda representam uma porcentagem muito pequena, de apenas 6\%. Mas este é um dado que não pode ser desprezado porque o assistente social supervisor, enquanto trabalhador, também está sujeito às mudanças no mundo do trabalho e, mesmo permanecendo majoritariamente na condição de trabalhador tipicamente assalariado e vinculado ao poder público, terá cada vez mais que estar preparado para se inserir em novos espaços sócio ocupacionais e ampliar a atuação na esfera da gestão. Os indicadores da pesquisa inserção ocupacional, rotatividade e tempo de permanência dos supervisores não se mostram explicitamente no cotidiano, uma vez que os profissionais tem acesso à proteção social, mas são indicadores que não deixam de ter um vínculo com a divisão social do trabalho. Portanto, não é possível desconsiderar a atual crise brasileira no que diz respeito à previdência social e ao desmonte dos direitos adquiridos historicamente pela classe trabalhadora, o que coloca em pauta uma desigualdade social do trabalho. "Com a divisão do trabalho [...] dá-se ao mesmo tempo a distribuição, com efeito a distribuição desigual, tanto quantitativa como qualitativamente, do trabalho e de seus produtos” (MARX e ENGELS, 1987, p. 46). As relações de dominação e subordinação características da sociedade capitalista refletem a desigualdade social e, por princípio, são alienantes porque decorrem do modo de produção que determina a divisão social do trabalho. "Las relaciones de inferioridad-superioridad (que, repetimos, reflejan el lugar ocupado de un modo permanente en la división social del trabajo) son, por tanto, relaciones de desigualdad social y como consecuencia son por principio alienantes”. Esta relação só irá mudar “cuando cambiar el lugar del particular en la división del trabajo” (HELLER, 1991, p. 360).

Na sociedade capitalista, a igualdade tem a propensão de advir daqueles que compartilham da mesma divisão social do trabalho, e, se não compartilham dela, a relação é caracterizada pela desigualdade social. "En las sociedades de clase los contactos basados en la igualdad son correlativos a los basados en la desigualdad” (HELLER, 1991, p. 361), ou seja, a igualdade é proporcionalmente correspondente à igualdade da divisão do trabalho. É importante lembrar que, para Heller (1987, p. 87), a classe social não pode ser confundida com comunidade, "embora os interesses e as funções dos membros de uma classe sejam idênticos em todos os aspectos essenciais”.

Entre os supervisores na maioria vinculados ao poder público 63\% atuam na área da assistência social, e os demais 37\% estão distribuídos entre as outras políticas sociais, ficando em segundo lugar a área da saúde. A contratação dos profissionais tem ocorrido com maior ênfase em função da legislação ${ }^{10}$ vigente para a implantação da Política Nacional de Assistência Social. Esta política prevê a necessidade da contratação do assistente social nas várias esferas públicas; por exemplo, os municípios de pequeno porte (até 2.500 famílias referenciadas) deverão ter no mínimo um assistente social, na equipe dos Centros de Referência da Assistência Social - CRAS. Conforme o porte do município o número de profissionais aumenta, bem como o número correspondente para a proteção especial (BRASIL, NOB-RH/SUAS, 2006, p. 23).

Com destaque à área da Assistência Social, podemos identificar as condições de precarização dos supervisores a partir de dois indicadores, um relacionado ao espaço sócio ocupacional e o outro especificamente à supervisão direta com o acadêmico.

O indicador espaço socioinstitucional, diz respeito a três segmentos em que o profissional mantém contato cotidiano: em relação à própria organização e gestão, em relação ao usuário e em relação à supervisão direta com o acadêmico. Relacionando este indicador com a interpretação helleriana, podemos dizer que existe uma relação de dependência ou autonomia relativa do supervisor.

Em relação ao espaço socioinstitucional, a maioria dos profissionais, 82\%, mencionam as seguintes situações: a falta de valorização do profissional (os profissionais percebem que os gestores nem sempre valorizam a prática profissional ou deixam de reconhecer e estimular as ações positivas e que proporcionam resultados positivos); a pressão para o cumprimento das atividades (um exemplo citado foi que o tempo previsto para o atendimento ao usuário com qualidade sofre uma pressão indireta na medida em que a sala de espera permanece lotada para atendimento); a carência de investimento institucional e governamental (um dos exemplos citados foi a falta de infraestrutura para atendimento ao usuário, assegurando-lhe sigilo profissional e respeitando o código de ética). Este aspecto se relaciona com a falta de qualidade na prestação de serviços oferecida pela organização.

A sobrecarga de trabalho é mencionada por $78 \%$ dos profissionais, que se reportam às dificuldades de dar conta da demanda porque não existe número suficiente de profissionais, o que acaba gerando falta de qualidade no atendimento aos usuários, bem como o acúmulo de funções. A política de recursos humanos é um 
dos eixos estruturantes, e um dos princípios da gestão do SUAS prevê o preenchimento de cargos através de concurso para "suprir as necessidades dos serviços" (BRASIL, NOB-RH/SUAS, 2006, p. 19).

Sobre a falta de tempo para atualização profissional, foi citada a dificuldade de participar das reuniões de formação para supervisores promovidas pelas Universidades: “Tenho tentado participar dos eventos proporcionados pelas Universidades e pela categoria profissional, de um modo geral. Contudo, a grande demanda de trabalho impede a participação" (AS 04). Cabe lembrar que está prevista na NOB-RH/SUAS uma política de capacitação continuada e sistemática. É interessante destacar que o profissional que aceita a função de supervisor, na maioria das vezes, faz isso porque se sente responsável pela formação dos futuros profissionais bem como pelo projeto ético-político profissional. Esta atribuição de supervisor deveria ser compreendida pelos gestores como uma responsabilidade da categoria; no entanto, a pesquisa demonstra que a responsabilidade pela supervisão tem sido uma opção individual do profissional, porque geralmente não existe incentivo para o desempenho de tal atribuição; ele precisa dar conta da demanda já instaurada, acrescentando a ela a demanda advinda da supervisão. Isso indica a necessidade de se repensar formas que valorizem e incentivem a atribuição privativa da função de supervisão. Na NOB-RH/SUS está prevista a "criação de um plano de carreiras, cargos e salários" (BRASIL, NOB-RH/SUAS, 2006, p. 17). Nesse sentido, seria interessante que a atribuição de supervisor fizesse parte do plano de carreira, demonstrando reconhecimento e valorização dessa atribuição.

A precarização na área da assistência pela ausência do cumprimento da legislação no que diz respeito à contratação da equipe necessária para atuar nos equipamentos da assistência faz com que ocorra uma sobrecarga do trabalho profissional, dando início a um círculo vicioso, pois isso também rebate no aluno em processo de supervisão, visto que as condições que lhe são impostas são condições de uma imediaticidade no atendimento a uma crescente demanda, implicando uma degeneração qualitativa nas condições de trabalho.

Não podemos deixar de mencionar que todas as condições de precarização mencionadas irão, de uma forma direta ou indireta, refletir-se na relação entre supervisor e acadêmico. Na relação que se estabelece no processo de supervisão pode-se considerar que existe uma dependência provisória. Esta, segundo Heller (1991), não pode ser compreendida como algo permanente, pois, ao se concretizar na esfera da particularidade, a dependência pode implicar uma condição de guia; por exemplo: o supervisor guia o estagiário no processo de aprendizado, de descoberta do ser profissional, na constituição da identidade profissional e na concretização do projeto ético-político da formação. A condição de guia se estabelece porque existe uma diferença de saberes, de experiência de vida, de concepção de mundo. Esta concepção helleriana tem afinidade com a defendida por Freire (1980) quando se refere à diferença de saberes entre educadores e educandos e afirma que a troca de conhecimento ocorrerá através do diálogo. Cada um carrega um saber e uma experiência vivida no cotidiano, e elas sempre serão diferentes, mas necessárias para serem compartilhadas e objetivadas. "Considero de grande importância a atuação de estágio no campo, porque, orientamos na prática, mas eles atualizam os nossos conhecimentos, quando nos informam o que aprenderam, as teorias que embasam suas práticas, tudo isso fortalece o nosso saber e do estagiário” (AS 15).

Segundo Heller (1987, p. 37), a dependência provisória não pode ser confundida com a alienação; apesar de que a "vida cotidiana, de todas as esferas da realidade, é aquela que mais se presta à alienação", não pode ser considerada alienante a desigualdade cuja natureza decorre de uma dependência, pois não determina a totalidade das relações sociais. "Pero esta desigualdad (no-alienada) es siempre temporal, o bien surge en cierto punto de la actividad sin determinar la totalidad de las relaciones interpersonales" (HELLER, 1991, p. 361). Portanto, a relação que se estabelece entre estagiário e supervisor não pode ser considerada alienante.

No tocante à forma como a precarização das condições de trabalho interfere no indicador processo de supervisão direta de estágio, $59 \%$ apontam o tempo insuficiente para elaboração de planos, programas e projetos em conjunto com o estagiário; $44 \%$ se referem ao tempo insuficiente para planejar atividades, para atualizar a documentação utilizada no campo; $16 \%$ ressaltam a falta de tempo para supervisão individual; $13 \%$, a impossibilidade de acompanhar todos os atendimentos realizados pelo estagiário, que acaba atendendo a demanda do serviço sem a presença do supervisor; $13 \%$, acúmulo de demandas, o que faz com que o supervisor não tenha tempo para a supervisão direta com o aluno; outros profissionais relatam a pressão que o estagiário sofre por parte da gestão, para atender 50 famílias no CADúnico; falta de tempo para refletir sobre o exercício profissional - enfim, a falta de tempo tem uma posição de destaque e caracteriza a precarização das condições de trabalho, embora nem sempre os profissionais identifiquem a falta de tempo como uma característica da precarização. Se, por um lado, a falta de tempo é o maior indicador das condições de precarização do trabalho que estão sendo vivenciadas pelos supervisores, por outro lado, não se pode esquecer que o tempo é uma "fonte de poder" em que o sistema vigente se reproduz. "na sociedade capitalista em particular, a intersecção do domínio sobre o dinheiro, o tempo e o espaço forma um nexo substancial de poder social que não podemos nos dar ao luxo de ignorar" (HARVEY, 2014, p. 207). A falta de tempo nem sempre é considerada pelos 
supervisores de campo como um indicador da precarização das condições de trabalho; por isso, esse poder se vale de uma invisibilidade cotidiana, presente na divisão social do trabalho.

É possível constatar que a relação do contato cotidiano, por si só, é oposta, contraditória e desigual, porém Heller (1991, p. 363) ressalta que o oposto da desigualdade é a igualdade livre, na relação direta que não é determinada pela divisão do trabalho. Assim se resgata a importância da relação do homem com o homem, de uma relação de igualdade livre, do contato cotidiano, enquanto uma atividade política consciente:

las relaciones cotidianas reflejan las relaciones existentes en el conjunto social. Resulta evidente que la totalidad de las relaciones personales de una persona o de un grupo no puede darnos una imagen clara de las relaciones sociales, pero, por el contrario, toda relación personal refleja algo de la naturaleza de la totalidad social. [...] Cuanto más numerosas son las relaciones interpersonales que surgen sobre una base de libre igualdad, tanto más humanizada está la sociedad.

\section{Considerações finais}

O cotidiano dos profissionais assistentes sociais supervisores de campo está totalmente interligado ao desenvolvimento e às mudanças no sistema capitalista. Principalmente ao longo da década de 1990, no campo de trabalho dos assistentes sociais, sobretudo no caso daqueles que trabalham enquanto funcionários públicos, assistiu-se a uma intensa precarização das condições de trabalho, por parte dos ideólogos do neoliberalismo em sucatear os serviços públicos, buscando dificultar o financiamento das políticas sociais. Esses elementos conformam a precarização do trabalho, fenômeno que atingiu todas as esferas do mundo do trabalho, onde se flexibilizaram direitos sociais trabalhistas, aumentando o desemprego e a inserção em postos de trabalho sem proteção social. Essa conjuntura impacta diretamente na supervisão de campo, pois se, por um lado, há uma redução dos gastos com a área social e a precarização das relações de trabalho, por outro, temos a falta de tempo, devido ao grande aumento das demandas que chegam ao assistente social, e muitas vezes não há profissionais suficientes para dar conta dessas demandas. Isso atinge diretamente a supervisão de campo e o processo de ensino e aprendizagem dos estudantes, em que sua formação fica afetada devido a esse contexto de precarização. Apontar esses elementos é primordial para que possamos fazer um exame crítico das situações de precarização, buscando articular processos de resistência com as entidades representativas, bem como com outras organizações da classe trabalhadora, visualizando no horizonte a construção de uma sociedade socialmente justa.

Enfim, podemos tirar a seguinte conclusão: a precarização das condições de trabalho que ocorre na supervisão pode ser compreendida tendo como eixo central o contato direto. Este contato, quando é determinado pela divisão do trabalho, também está sujeito a uma relação de dominação e de desigualdade resultante do modo de produção capitalista. Quando o contato é determinado pela relação direta entre os sujeitos, poderá gerar uma dependência provisória, mas é ao mesmo tempo o lócus privilegiado do desenvolvimento da consciência de classe, que, quando vinculada a toda a classe trabalhadora, poderá se caracterizar como uma atividade política consciente.

\section{Referências}

ALVES, G. Trabalho e subjetividade: o espírito do toyotismo na era do capitalismo manipulatório. São Paulo: Boitempo Editorial, 2011. ANDERSON, P. Balanço do neoliberalismo. In: SADER, E.; GENTILLI, P. Pós-neoliberalismo: as políticas sociais e o Estado democrático. Rio de Janeiro: Paz e Terra, 1995. p. 09-23.

ANTUNES, R. Adeus ao trabalho? Ensaio sobre as metamorfoses e a centralidade do mundo do trabalho. São Paulo: Cortez, 1995. BEHRING, E. R. Brasil em contra-reforma: desestruturação do Estado e perda de direitos. São Paulo: Cortez, 2003.

BOITO Jr., A.; BERRINGER, T. Brasil: Classes sociais, neodesenvolvimentismo e política externa nos governos Lula e Dilma. Revista de Sociologia e Política, v. 21, n. 47, p. 31-38, set. 2013.

BRASIL, NOB/RH/SUAS. Norma Operacional de Recursos Humanos do SUAS. Brasília: MDS, 2006.

CASTELO, R. O novo desenvolvimentismo e a decadência ideológica do pensamento econômico brasileiro. Revista Serviço Social e Sociedade, São Paulo, n. 112, p. 613-636, out./dez. 2012.

FAGNANI, E. A política social no Governo Lula (2002-2010): perspectiva histórica. Campinas: IE/UNICAMP, jun. 2011. Disponível em: http://www.eco.unicamp.br/publicações. Acesso em: 24 jan. 2016.

FREIRE, P. Conscientização: teoria e prática da libertação. São Paulo: Moraes, 1980.

HARVEY, D. Condição pós-moderna. São Paulo: Loyola, 2014. 
HELLER, A. O cotidiano e a história. Tradução de Carlos Nelson Coutinho e Leandro Konder. Rio de Janeiro: Paz e Terra, 1987. . Sociología de la vida cotidiana. Traducción de Montserrat Gurguí. Barcelona: Ediciones Peninsula, 1991.

LIMA, K. Contra-reforma na Educação Superior: de FHC a Lula. S. Paulo: Xamã, 2007.

LUSTOSA, M. G. O. P. Reforma Agrária à brasileira: política social e pobreza. São Paulo: Cortez, 2012.

MARTINS, M. D. O Banco Mundial e a Terra: ofensiva e resistência na América Latina, África e Ásia. São Paulo: Viramundo, 2004.

MARX, K.; ENGELS, F. A ideologia alemã. São Paulo: HUCITEC, 1987.

NETTO, J. P.; BRAZ, M. Economia Política: uma introdução crítica. São Paulo: Cortez, 2007.

PEREIRA, P. A. P. Utopias desenvolvimentistas e política social no Brasil. Revista Serviço Social e Sociedade, São Paulo, n. 112, p. 729-753, out./dez. 2012.

PINTO, G. A. A organização do trabalho no século XX. São Paulo: Editora Expressão Popular, 2013.

POSTONE, M. Tempo, trabalho e dominação social: uma reinterpretação da teoria crítica de Marx. São Paulo: Boitempo, 2014.

SILVA E SILVA, M. O. O Serviço Social e o popular: resgate teórico-metodológico do projeto profissional de ruptura. São Paulo: Cortez, 2007.

TAVARES, M. A. Os fios (in)visíveis da produção capitalista: informalidade e precarização do trabalho. São Paulo: Cortez, 2004.

TONI, M. D. Precarização do trabalho a partir dos anos 90: reversão de tendências no período recente? In: BASTOS, R. L. A. et al. Dimensões da precarização do mercado de trabalho na Região Metropolitana de Porto Alegre. Porto Alegre: FEE, 2007. p. 17-80.

WÜNSCH, P. R. Sindicalismo e reestruturação produtiva no Brasil: desafios da ação sindical dos metalúrgicos de Caxias do Sul/RS. Bauru: Canal 6 Editora, 2013.

\section{Notas}

1 A sistematização dos dados contou com a participação de bolsistas de iniciação científica: Juliana Souza Ribeiro, da PROBITI/ FAPERGS; João Vitor Bitencourt, da PIBIQ/FAPERGS; Jorge Gomes de Oliveira, do PIBIQ/CNPQ, bem como a mestranda Rossana Lopes Pereira de Souza e a doutoranda Thiana Orth, do Programa de Pós-Graduação em Serviço Social da PUCRS.

2 Essa crise teve como elementos os desequilíbrios nas contas externas na maioria dos países devido ao súbito aumento do preço do petróleo pela Organização dos Países Exportadores de Petróleo (OPEP), além das sucessivas desvalorizações e valorizações do dólar, praticamente impostas pelos EUA, gerando as primeiras grandes variações nas taxas de câmbio das economias nacionais (PINTO,2013).

3 A acumulação flexível marca "um confronto direto com a rigidez do fordismo. Ela se apoia na flexibilidade dos processos de trabalho, dos mercados de trabalho, dos produtos e padrões de consumo” (HARVEY, 2014, p. 140).

4 Segundo Netto e Braz (2007), com o fim do período dos "anos dourados”, a taxa de lucro nos países centrais teve um intenso processo de descenso: entre 1968 e 1973, naAlemanha Ocidental, foi de 16,3\% para 14,2\%, na Grã-Bretanha, de 11,9\% para 11,2\%, na Itália, de 14,2\% para 12,1\%, nos Estados Unidos, de 18,2\% para 17,1\%, e no Japão, de 26,2\% para 20,3\%.

5 Cf.Lima(2007), Lustosa(2012)e Martins(2004).

6 Cf.Boito Jr. e Berringer(2013).

7 Estes indicadores foram definidos a partir das categorias de análise identificadas na pesquisa empírica, realizada com supervisores de campo do Serviço Social.

8 Os indicadores condição de inserção ocupacional e tempo de permanência no emprego foram utilizados com base em Toni (2007).

9 Os dados quantitativos apresentados derivam de uma amostra de 38 profissionais e os discursos de uma amostra de 78 profissionais.

10 Desde 1993, com a Lei Orgânica de Assistência Social, em 2004 com a Política Nacional deAssistência Social, em 2005 com a criação da rede do Sistema Único de Assistência Social (SUAS), em 2006 com a aprovação da Norma Operacional de Recursos Humanos do SUAS. A partir disso, várias outras resoluções e normativas são estabelecidas, constituindo um conjunto de ações que garantem a Assistência Social como política pública e dever do Estado.

\section{Gleny Terezinha Duro Guimarães}

gleny@pucrs.br

Doutora em Serviço Social pela Pontifícia Universidade Católica de São Paulo (PUCSP)

Professora de Serviço Social na Pontifícia Universidade Católica do Rio Grande do Sul (PUCRS)

\section{Paulo Roberto Martins}

paulomartins_rs@hotmail.com

Mestrando em Serviço Social pela Pontifícia Universidade Católica do Rio Grande do Sul (PUCRS)

Assistente Social da Universidade Federal de Santa Maria (UFSM) 


\section{PUCRS}

Av. Ipiranga, 6681 - Prédio 15, Bairro Partenon

Porto Alegre - Rio Grande do Sul - Brasil

CEP: 90619-900

\section{UFSM}

Av. Roraima, 1000 - Camobi

Santa Maria - Rio Grande do Sul - Brasil

CEP: 97105-900

\section{ERRATA}

No artigo "Supervisão em Serviço Social diante da precarização no mundo do trabalho: uma perspectiva helleriana” de Gleny Terezinha Duro Guimarães e Paulo Roberto Martins, com número de DOI: 10.1590/141449802016.003.00007, publicado no periódico Revista Katálysis, v. 19, n. 3, out./dez. 2016, na página 378:

Onde se lia:

“Mestre em Serviço Social pela Pontifícia Universidade Católica de São Paulo (PUCSP)"

Leia-se:

“Mestrando em Serviço Social pela Pontifícia Universidade Católica de São Paulo (PUCSP)" 